\begin{tabular}{|c|c|c|}
\hline \multirow{3}{*}{$\begin{array}{r}\text { Case Reports in } \\
\text { Gastroenterology }\end{array}$} & \multirow{2}{*}{\multicolumn{2}{|c|}{ Case Rep Gastroenterol 2014;8:206-210 }} \\
\hline & & \\
\hline & $\begin{array}{l}\text { DOI: 10.1159/000364821 } \\
\text { Publisned online: June } /, 2014\end{array}$ & $\begin{array}{l}\text { (c) } 2014 \text { S. Karger AG, Basel } \\
\text { 1662-0631/14/0082-0206 } \$ 39.50 / 0 \\
\text { www.karger.com/crg }\end{array}$ \\
\hline & \multicolumn{2}{|c|}{$\begin{array}{l}\text { This is an Open Access article licensed under the terms of the Creative Commons } \\
\text { Attribution-NonCommercial } 3.0 \text { Unported license (CC BY-NC) (www.karger.com/OA- } \\
\text { license), applicable to the online version of the article only. Distribution permitted for non- } \\
\text { commercial purposes only. }\end{array}$} \\
\hline
\end{tabular}

\title{
Successful Retrieval of a Retained Capsule Endoscope with Single Incision Laparoscopic Surgery
}

\author{
Yoshihiko Tashiro $^{\mathrm{a}}$ Masaya Kawai $^{\mathrm{a}}$ Kazuhiro Takehara ${ }^{\mathrm{a}}$ \\ Shinya Munakata ${ }^{a}$ Shun Ishiyama $^{a}$ Kiichi Sugimoto $^{a}$ \\ Makoto Takahashi ${ }^{a}$ Yutaka Kojima $^{a}$ Michitoshi Goto ${ }^{a}$ \\ Yuichi Tomiki ${ }^{a}$ Tomoyoshi Shibuya $^{\mathrm{b}}$ Taro Osada ${ }^{\mathrm{b}}$ \\ Sumio Watanabe ${ }^{b}$ Kazuhiro Sakamoto ${ }^{a}$ \\ Departments of ${ }^{a}$ Coloproctological Surgery and ${ }^{b}$ Gastroenterology, Juntendo University \\ Faculty of Medicine, Tokyo, Japan
}

\section{Key Words}

Single incision laparoscopic surgery · Capsule retention · Capsule endoscopy

\begin{abstract}
Capsule endoscopy (CE) is commonly used for examining and diagnosing gastrointestinal disease, especially small bowel disease. Capsule retention is a well-known and significant complication of $\mathrm{CE}$ and requires surgical or endoscopic removal. Most reports described the retrieval of retained CE via laparotomy. We report a case of successful retrieval of the capsule using single incision laparoscopic surgery.

(C) 2014 S. Karger AG, Basel
\end{abstract}

\section{Introduction}

Capsule endoscopy (CE) is increasingly used for the evaluation of small bowel disease. The ease of use and patient tolerance of $\mathrm{CE}$ has made it popular among gastroenterologists and patients. Currently, CE is most commonly used to identify the origin of obscure gastrointestinal bleeding, but its indications are broadening. Various reports have described impaction or retention of the capsule in the small bowel that required retrieval. Despite the low risk of complications, capsule retention occurs in 1-3\% of cases [1]. Capsule retention may reveal the underlying cause of the gastrointestinal disease, but can cause acute in- 
Tashiro et al.: Successful Retrieval of a Retained Capsule Endoscope with Single Incision Laparoscopic Surgery

testinal obstruction and perforation requiring surgery. Here, we describe a case of retained capsule that was retrieved with single incision laparoscopic surgery (SILS).

\section{Case Report}

A 43-year-old man with no past medical history presented to our hospital for investigation of anemia and a positive fecal occult blood test. Laboratory data showed a hemoglobin level of $11.2 \mathrm{~g} / \mathrm{dl}$. The cause of the gastrointestinal bleeding could not be determined despite gastroscopy and colonoscopy. The small bowel was therefore examined using CE (PillCam $^{\mathrm{TM}}$ SB2, Given Imaging, Yokneam, Israel). The patient was unable to pass the capsule more than 2 weeks after ingestion but did not have pain or symptoms of bowel obstruction. Abdominal $\mathrm{X}$-ray showed the retained capsule in the right side of the abdomen, and an abdominal CT revealed the capsule in the small bowel. To confirm the diagnosis and retrieve the capsule, enteroscopy with a double-balloon enteroscope (EN-450T5/W, Fujifilm, Tokyo, Japan) was performed under fluoroscopic guidance via the anal route. The double-balloon enteroscopy revealed a circumferential stricture with an ulcer and giant diverticulum in the small intestine $2 \mathrm{~m}$ proximal to the ileocecal valve (fig. 1a). We performed bougie dilatation for the stricture, but the enteroscope was unable to move past the stricture. Small bowel contrast imaging using Gastrografin at the time of CE revealed two more strictures at the anal side. The capsule was retained in the proximal intestine lumen (fig. 1b). We performed tattoo injection close to the distal stricture for the operation. The patient was diagnosed with CE retention secondary to stricture of the small intestines. As it was impossible to retrieve the retained capsule using an enteroscope, SILS was performed to resect the small bowel containing the CE and stricture after obtaining written informed consent from the patient.

After administration of general anesthesia, a 4-cm incision was made through the umbilicus. An EZ Access ${ }^{\mathrm{TM}}$ (Hakko Medical, Nagano, Japan) was placed around the umbilical incision. A 12-mm camera port (XCEL ${ }^{\mathrm{TM}}$ Trocar, Ethicon Endo-Surgery, Inc., Cincinnati, Ohio, USA) and two 5-mm trocars (YelloPort ${ }^{\mathrm{TM}}$, Surgical Innovations, Leeds, UK) were inserted through the EZ Access. A pneumoperitoneum with a pressure of $10 \mathrm{~mm} \mathrm{Hg}$ was created and a 10-mm rigid 30-degree laparoscope (Karl Storz Endoscopy, Tuttlingen, Germany) was used. Laparoscopy revealed an edematous bowel with erythema $2 \mathrm{~m}$ proximal to the ileocecal valve where the stricture was presumably located, and the tattoo of the small bowel was identified (fig. 2a). After the trocars and the lap protector had been removed, the affected small bowel was brought outside the abdomen and resected (fig. 2b). A functional end-to-end anastomosis was performed using a GIA ${ }^{\mathrm{TM}}$ stapler with a 80-3.8 cartridge (Covidien, Mansfield, Mass., USA). The anastomosis, without signs of bleeding, was then pushed back into the abdomen and the incision was closed (fig. 2c). The histopathological diagnosis was Crohn's disease with ulcer and stricture of the ileal segment (fig. 3). The patient's recovery was uneventful and he was discharged home on postoperative day 8. After discharge, he was treated with salazosulfapyridine for Crohn's disease.

\section{Discussion}

CE has become an important modality in the evaluation of small bowel disease since its introduction by Iddan et al. in 1999 [2]. The advantages of CE include noninvasiveness, simplicity and safety, but the possibility of CE retention exists. Capsule retention was defined by the International Conference on Capsule Endoscopy (ICCE) in 2005 as the presence of a 
Tashiro et al.: Successful Retrieval of a Retained Capsule Endoscope with Single Incision Laparoscopic Surgery

capsule in the digestive tract for at least 2 weeks or requiring directed medical, endoscopic or surgical intervention [3].

The rate of capsule retention is variable and is influenced by the clinical indication for CE $[4,5]$. The reported rates were $0 \%$ in healthy individuals, $1.4 \%$ in patients with obscure gastrointestinal bleeding, 5-13\% in those with suspected Crohn's disease and $21 \%$ in patients with intestinal obstruction [4]. Of 22,840 procedures identified in a systematic review of both prospective and retrospective studies by Liao et al. [5], 184 capsule retentions occurred, resulting in a pooled retention rate of $1.4 \%$, with $1.2,2.6$ and $2.1 \%$ occurring in cases with obscure gastrointestinal bleeding, Crohn's disease and neoplastic lesions, respectively [5]. Other causes of retention were nonsteroidal anti-inflammatory drug-induced enteropathy, postoperative stenosis, adhesions, tuberculosis, ischemia and radiation enteritis [5]. Our patient was originally investigated for obscure gastrointestinal bleeding and had no symptoms of bowel obstruction. Therefore, it was difficult to predict the risk of capsule retention. No methods exist, including imaging studies, that can predict the occurrence of capsule retention.

Retention of the capsule is usually asymptomatic, but sometimes causes partial bowel obstruction [6]. Capsule retention indicates the presence of underlying pathology and thus helps in identifying the etiology and site of obstruction. The longest duration of retention reported by the ICCE is 2.5 years, but sequelae associated with long-term capsule retention were not reported [7].

Usually, retained capsules can be extracted with surgery or enteroscopy. Some reports advocated surgical intervention that allows removal of both the capsule and the pathology that caused the capsule retention [5, 6]. In a systematic review of 184 capsule retentions by Liao et al. [5], retained capsules were recovered through spontaneous excretion or by pharmaceutical intervention in $15 \%$, endoscopically in $12 \%$ and surgically in $58.7 \%$ of cases. Studies by Baichi et al. [8] and Yang et al. [6] also described surgical recovery of CE in $>50 \%$ of cases.

Endoscopic retrieval and extraction by push-and-pull enteroscopy using the doubleballoon technique have been reported, but subsequent surgical retrieval is often required because of the underlying pathology that caused the stricture or obstruction. These studies suggest that the majority of patients eventually require surgical retrieval. Most cases of surgical retrieval were laparotomies despite the benign nature of the diseases that caused the CE retention. Dominguez et al. [9] reported a successful case of laparoscopic retrieval for CE retention. Laparoscopic surgery enables a better cosmetic outcome, reduced pain and shorter hospital stays. SILS further reduces the invasiveness of surgery. By creating a single laparoscopic incision, the risk of organ injury, hemorrhage and postoperative adhesions is reduced [10]. Patient acceptance and satisfaction associated with the single incision are also high. However, surgeons should quickly convert the procedure to laparotomy or add ports to avoid complications that arise due to technical difficulties in SILS. Successful outcomes can be expected in patients with retained capsules if the principles of safe laparoscopic surgery, including stringent patient selection, are followed.

\section{Disclosure Statement}

The authors have no conflicts of interest or financial ties to disclose. 


\section{Case Reports in
Gastroenterology}

\begin{tabular}{l|l}
\hline Case Rep Gastroenterol 2014;8:206-210 \\
\hline DOI: 10.1159/000364821 & $\begin{array}{l}\text { @ 2014 S. Karger AG, Basel } \\
\text { www.karger.com/crg }\end{array}$ \\
\hline
\end{tabular}

Tashiro et al.: Successful Retrieval of a Retained Capsule Endoscope with Single Incision Laparoscopic Surgery

\section{References}

1 Remedios ML, Appleyard M: Capsule endoscopy: current indications and future prospects. Intern Med J 2005;35:234-239.

2 Iddan G, Meron G, Glukhovsky A, Swain P: Wireless capsule endoscopy. Nature 2000;405:417.

-3 Chang PK, Holt EG, De Villiers WJ, Boulanger BR: A new complication from a new technology: what a general surgeon should know about wireless capsule endoscopy. Am Surg 2005;71:455-458.

4 Mata A, Llach J, Bordas JM: Wireless capsule endoscopy. World J Gastroenterol 2008;14:1969-1971.

5 Liao Z, Gao R, Xu C, Li ZS: Indications and detection, completion, and retention rates of small-bowel capsule endoscopy: a systematic review. Gastrointest Endosc 2010;71:280-286.

6 Yang XY, Chen CX, Zhang BL, Yang LP, Su HJ, Teng LS, Li YM: Diagnostic effect of capsule endoscopy in 31 cases of subacute small bowel obstruction. World J Gastroenterol 2009;15:2401-2405.

7 Cave D, Legnani P, de Franchis R, Lewis BS: ICCE consensus for capsule retention. Endoscopy 2005;37: 1065-1067.

8 Baichi MM, Arifuddin RM, Mantry PS: What we have learned from 5 cases of permanent capsule retention. Gastrointest Endosc 2006;64:283-287.

9 Dominguez EP, Choi Y, Raijman IL, Sweeney JF: Laparoscopic approach for the retrieval of retained video capsule endoscopy. JSLS 2006;10:496-498.

10 Leroy J, Cahill RA, Peretta S, Marescaux J: Single port sigmoidectomy in an experimental model with survival. Surg Innov 2008;15:260-265.
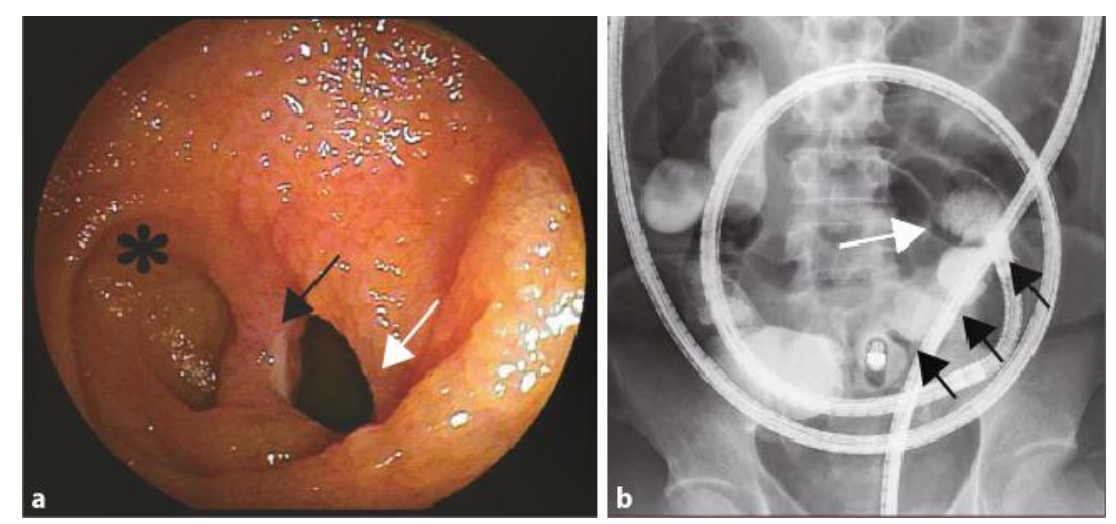

Fig. 1. a Retrograde double-balloon enteroscopy revealed a diverticulum (asterisk) and a shallow ulcer (black arrow) on the edge of the stenosis (white arrow). b Fluoroscopy revealed the presence of the retained capsule, multiple strictures (black arrows) and a giant diverticulum (white arrow) in the distal small intestines. 
Tashiro et al.: Successful Retrieval of a Retained Capsule Endoscope with Single Incision Laparoscopic Surgery
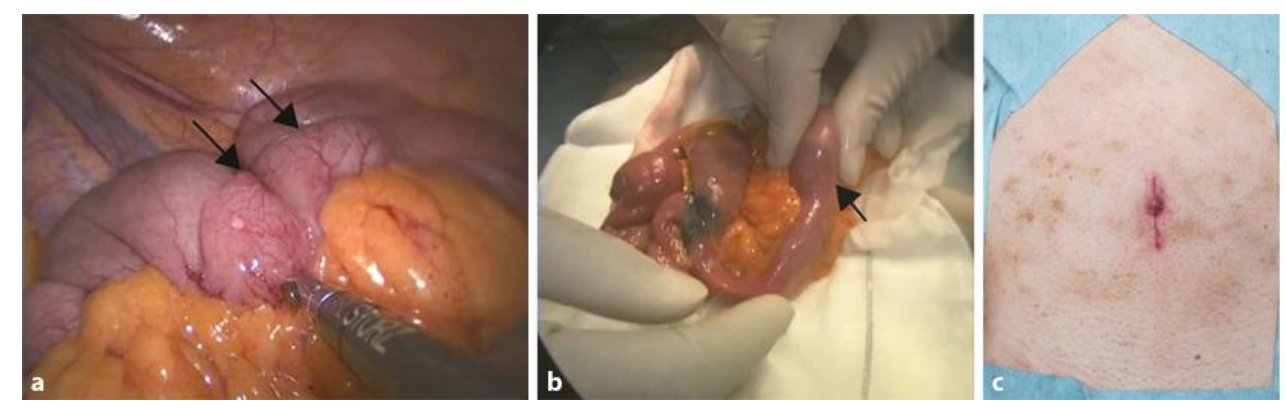

Fig. 2. a Intraoperative examination of the small bowel revealed features suggestive of strictures (arrows) in the ileum $2 \mathrm{~m}$ proximal to the ileocecal valve and a bulge consistent with the presence of the retained capsule. $\mathbf{b}$ The operative findings confirmed the presence of the retained capsule in the ileum (arrow). c The umbilical incision after surgery.
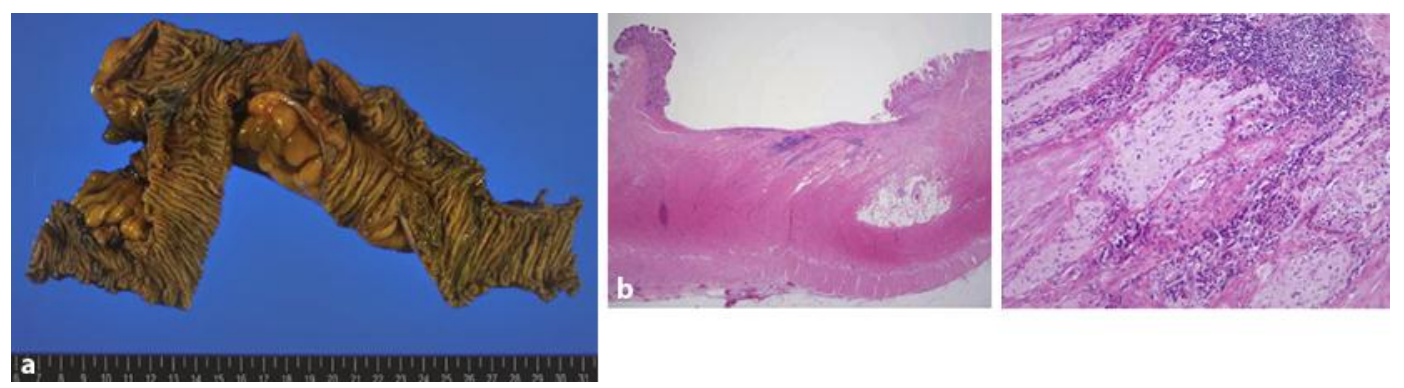

Fig. 3. a The resected specimen of the small bowel. A stricture causing narrowing of the small bowel lumen and capsule retention was present. b Histopathological findings (hematoxylin and eosin staining). An ulcer in the submucosal layer (left-hand image, magnification $\times 40$ ) and transmural inflammation mainly composed of lymphocytes (right-hand image, magnification $\times 200$ ) were seen. 